occurs. In attempts to bridge this gap, high-quality, relevant and up-to-date systematic reviews and evidence-based guidelines are both important tools. The processing of a systematic review and the development of an evidence-based guideline show a lot of similarities in undertaking research syntheses, developing methods for identifying, appraising, and synthesising evidence, and in translating research evidence into practice and policy. International organisations like Cochrane Collaboration and Guidelines International Network (G-I-N) collaborate in the development and adoption of tools like GRADE to rate the quality of evidence and to grade the strength of recommendations.

However, also differences can be identified. While systematic reviews investigate and summarise the scientific literature on effects of exposures, interventions, or diagnostic procedures in a systematic and methodologically rigorous way, it is clear that decision making in the field of OSH will seldom be based on research evidence alone but will incorporate professional expertise of professionals, ethical considerations, preferences and values of workers, and the policies of governments, companies and other stakeholders. Guidelines are defined as 'documents with recommendations to assist healthcare practitioners and healthcare users, intended to optimise quality of care, based on a systematic review of evidence and an assessment of the benefits and harms of the various care options, supplemented with expertise and experiences of both practitioners and users'. In particular when high quality evidence is not available, contradictory, or inappropriate, experiential and contextual knowledge may help guideline makers to formulate sensible recommendations.

\section{$1710 \mathrm{e}$ INTERVENTIONS TO INCREASE THE REPORTING OF OCCUPATIONAL DISEASES BY PHYSICIANS}

${ }^{1} S$ Curti, ${ }^{2} R$ Sauni* ${ }^{3} D$ Spreeuwers, ${ }^{4} A$ de Schryver, ${ }^{5} \mathrm{M}$ Valenty, ${ }^{6} S$ Rivière, ${ }^{1} S$ Mattioli. ${ }^{1}$ Department of Medical and Surgical Sciences, University of Bologna, Bologna, Italy; ${ }^{2}$ Department for Occupational Safety and Health, Ministry of Social Affairs and Health, Finland; ${ }^{3}$ Free University Medical Centre, Amsterdam, Netherlands; ${ }^{4}$ Epidemiology and Social Medicine, University of Antwerp, Antwerpen, Belgium; ${ }^{5}$ Département Santé Travail, Institut de Veille Sanitaire, Saint Maurice, France

\subsection{6/oemed-2018-ICOHabstracts.363}

Introduction Under-reporting of occupational diseases is an important issue worldwide. The collection of reliable data is essential for prevention programmes. Little is known about the effects of interventions for increasing the reporting of occupational diseases.

Methods We searched the Cochrane Occupational Safety and Health Group Specialised Register, the Cochrane Central Register of Controlled Trials (CENTRAL), MEDLINE (PubMed), EMBASE, OSH UPDATE, Database of Abstracts of Reviews of Effects (DARE), Open-SIGLE, and Health Evidence until January 2015. We also checked reference lists of relevant articles and contacted study authors.

Results We included 12 studies. Six studies evaluated the effectiveness of educational materials alone; one study evaluated the effectiveness of educational meetings; and four studies evaluated a combination of the two in increasing the reporting of occupational diseases by physicians. A further study evaluated the effectiveness of a complex educational campaign acting at society level. We found that the use of educational materials did not considerably increase the number of physicians reporting occupational diseases, but a legal obligation reminder message did. Furthermore, we found that the use of educational materials did not considerably increase the rate of reporting occupational diseases. Similarly, we found that the use of both educational materials and meetings did not considerably increase the number of physicians reporting occupational diseases or the rate of reporting. The same holds for the use of educational meetings alone. The use of an educational campaign appeared to increase the number of physicians reporting occupational diseases, although this was based on very low-quality evidence.

Discussion The studies provide evidence that educational materials, educational meetings, or a combination of the two do not considerably increase the reporting of occupational diseases. The use of a reminder message on the legal obligation to report might provide some positive results. We need highquality RCTs to corroborate these findings.

\section{$1710 f$ EMPTY REVIEWS: HOW, WHY OR WHY NOT?}

D FitzGerald. Medmark Occupational Healthcare, Cork, Ireland

\subsection{6/oemed-2018-ICOHabstracts.364}

Introduction Where no studies relevant to the scientific question being examined meet the pre-specified inclusion criteria, a systematic review becomes an 'empty review'. As such, no robust evidence based conclusions can be drawn from the findings of these reviews. It may be that such reviews have been undertaken where there is not yet a sufficient body of knowledge to allow for a systematic review being undertaken. In such circumstances, the publication of an empty systematic review may prompt the funding for and development of studies to answer the relevant scientific question. Also, in is much as there is a benefit in knowing what evidence based recommendations can be made in clinical practice, it is also useful to know what commonly used treatments are prescribed based on generally accepted standard practice rather than proven clinical benefit. It may also be, however, that the question being examined is too narrow or too focused, with excessively broad exclusion criteria, to be of relevance in a typical clinical setting. The development of such systematic reviews may be regarded as wasteful in resource limited circumstances.

\section{OVERVIEW OF EPICOH SPECIAL SESSION FOR ICOH 2018 - HIGHLIGHTED ISSUES IN OCCUPATIONAL EPIDEMIOLOGY}

Leslie London. School of Public Health and Family Medicine, University of Cape Town, South Africa

10.1136/oemed-2018-ICOHabstracts.365

Professors: ${ }^{1}$ Leon Guo, ${ }^{2}$ Po-Chin $\mathrm{Chu},{ }^{3} \mathrm{R}$ Mendes, ${ }^{4} \mathrm{O}$ Dumas, ${ }^{5}$ AM Neophytou

${ }^{1}$ National Institute of Environmental Health Sciences, National Health Research Institutes, Taiwan

${ }^{2}$ Environmental and Occupational Medicine, National Taiwan University College of Medicine and NTU Hospital, Taipei, Taiwan

${ }^{3}$ National Association of Occupational Medicine (ANAMT), São Paulo - SP, Brazil 
${ }^{4}$ INSERM, U1168, VIMA: Aging and chronic diseases. Epidemiological and public health approaches \& University Versailles Saint-Quentin-en-Yvelines, Villejuif, France

${ }^{5}$ Division of Environmental Health Sciences, School of Public Health, University of California, Berkeley, Berkeley, California, USA

\section{0a A RIGHTS-BASED APPROACH TO ACCESS TO OCCUPATIONAL HEALTH SERVICES - WHAT MIGHT THAT OFFER WORKING POPULATIONS IN THE DEVELOPING WORLD?}

Leslie London*. School of Public Health and Family Medicine, University of Cape Town, South Africa

\subsection{6/oemed-2018-ICOHabstracts.366}

The majority of workers worldwide remain without adequate access to Occupational Health Services (OHS), particularly with regard to gaps in implementation, coverage, content, and capacity building. Yet access to OHS is an essential element of the right to health and is recognised in numerous global human rights agreements as being a fundamental human right. Even in situations of resource scarcity, states have obligations to formulate, implement, monitor and evaluate occupational health laws and policies, and to facilitate the participation of workers in these activities. Rather than counting OHS as a cost to production, it is important to frame OHS as a valuedriven enterprise which can benefit all stakeholders, both employers and employees and provide a fair and accepted framework for managing conflicting interests. More importantly, OHS as a rights-based activity will reach beyond the traditional formal sector and challenge governments to address the $\mathrm{OH}$ needs of informal sector workers and other working populations currently lying outside of traditional regulatory perspectives - a particularly important requirement for Low and Middle-Income countries. Not all countries will enjoy the same resources to implement OHS's and rationing decisions may result in different levels of OHS provision. However, a Rights-based approach to OHS provision will identify basic OHS standards consistent with core obligations on states, will impose constitutional limits on the extent to which rationing decisions adversely impact on OHS provision, will force stakeholders to pursue equity-related policies and will open participatory spaces for citizens and communities to assert rights to workplace health and safety, across formal and informal sectors. This approach provides a huge opportunity for leverage for OHS in the developing world which $\mathrm{OH}$ practitioners should support through their research, service and advocacy.

\section{$1720 \mathrm{~b}$ IMPACTS OF OCCUPATIONAL HEALTH SERVICE NETWORK TO REPORTING OCCUPATIONAL DISEASES}

${ }^{1}$ Leon Guo*, ${ }^{2}$ Po-Chin Chu. ${ }^{1}$ National Institute of Environmental Health Sciences, National Health Research Institutes, Taiwan; ${ }^{2}$ Environmental and Occupational Medicine, National Taiwan University College of Medicine and NTU Hospital, Taipei, Taiwan

10.1136/oemed-2018-ICOHabstracts.367
Occupational disease are frequently underreported, therefore their importance in health consequences. This hinders the progress in occupational health and safety. To address this problem, several medical centres and the labour authority of Taiwan founded the Network of Occupational Diseases and Injuries Service (NODIS) for occupational disease and injury services and established a new Internet-based reporting system. The impacts of the Centres for Occupational Disease and Injury Services and their local network hospitals on compensable occupational diseases were analysed, and the distribution of occupational diseases across occupations and industries were described from 2005 to 2016. The NODIS reporting dataset and the National Labour Insurance scheme's dataset of compensated cases were used. The annual incidence of reported occupational diseases from the NODIS was compared with the annual incidence of compensable occupational diseases from the compensated dataset during the same period. It is found that after the establishment of the NODIS, the two annual incidence rates of reported and compensable occupational disease cases have increased by several folds from 2007 to 2016. The reason for this increased reporting and compensable cases may be the implementation of the new government-funded Internet-based system and increasing availability of hospitals and clinics to provide occupational health services. During the 2008-2016 period, the most frequently reported occupational diseases were carpal tunnel syndrome, lumbar disc disorder, upper limb musculoskeletal disorders, and contact dermatitis. It is concluded that the network and reporting system was successful in providing more occupational health services to workers, assisting the diagnosis of compensable occupational diseases, and reducing underreporting of occupational diseases. The experience in Taiwan could serve as an example for other newly developed countries facing underdiagnosis and under-reporting of occupational diseases.

\section{C OPPORTUNITIES TO INSERT OCCUPATIONAL HEALTH COMPONENTS INTO NATIONAL HEALTH POLICIES AND PROGRAMS: VIEWS AND EXPERIENCES}

R Mendes. National Association of Occupational Medicine (ANAMT), São Paulo - SP, Brazil

\subsection{6/oemed-2018-ICOHabstracts.368}

Several countries, like Brazil, where Workers' Health is a clear responsibility and mandate of the Ministry of Health, are supposed to develop health policies that include basic components of the 'Occupational Health thinking' and approaches. These components should be included into all levels of health services, depending on the mission, responsibility and complexity of each level, as well as on the geographical coverage and mandate. Such countries, fortunately, have structured their national system taking the Primary Health Care approach as the main 'organiser' of the whole health system. Primary Heath Care has received some variations, and the Brazilian case is based on the Family Heath Care approach, that may be an appropriate advancement. So, entering through the 'door' of the Health System - i.e. the Family Health Care approach or program - it is possible to reach and access the full System, from the primary level to more elevated and complex levels. The main components of the 'Occupational 